\title{
The Post-Research Ethical Obligations of the Research Enterprise in Developing Countries
}

Nida Khan*

MB, BS, MD (USA), M.Sc. Bioethics (AKUH), Karachi, Pakistan

${ }^{*}$ Corresponding author: Nida Khan, MB, BS, MD (USA), M.Sc. Bioethics (AKUH), Karachi, Pakistan, Tel: 92213486441 ; E-mail: enn.kay1@gmail.com

Rec date: Jan 03, 2014, Acc date: Apr 16, 2014, Pub date: Apr 20, 2014

Copyright: (c) 2014 Khan N, et al. This is an open-access article distributed under the terms of the Creative Commons Attribution License, which permits unrestricted use, distribution, and reproduction in any medium, provided the original author and source are credited.

\begin{abstract}
Undoubtedly, clinical research has become indispensable to the progress of modern medicine. Its value cannot be underestimated since it has been responsible for development of numerous life-saving and innovative drugs, medical diagnostic and therapeutic equipment, vaccines and nutritional supplements etc. in the past few decades. As the significance of research ethics amongst investigators, sponsors and their institutions takes center stage, there is a general trend toward a more responsible conduct of research. With the passage of time, more and more guidelines are being added and existing ones are being amended to include a previously unaddressed and oftneglected area of ethics regarding the conduct of clinical trials. According to the latest international guidelines governing human subjects' research, there is now a consensus that the ethical responsibilities of the research enterprise, do not cease once the clinical trial is over. This is particularly true in context of developing nations such as Pakistan, which is host to a lot of foreign multinationals and independent organizations conducting research. This paper attempts to highlight the post research responsibilities of the researcher, institution and the funding agency in light of the basic bioethics principles and theories.
\end{abstract}

Keywords: Clinical trials; International research; Research ethics; Developing countries; Post-trial provisions

\section{Background}

Let us begin by first examining what the previous international guidelines released by the World Medical Association said about postresearch responsibilities. The World Medical Association's Declaration of Helsinki (2008) stated that "at the conclusion of the study, every patient entered into the study should be assured of access to the best proven prophylactic, diagnostic and therapeutic methods identified by the study" [1]. The problem here lies, in the details. It was open to interpretation, just what "assured of access" meant in practical terms. The language needed to be more explicit in order to successfully implement the guidelines. The recent Declaration of Helsinki released by the World Medical Association in October 2013, has categorically elaborated a lot of the 'vagueness' in the previous guidelines; for instance, changing the timing of assured access to post-trial provisions from "at the conclusion of the study" to "in advance of a clinical trial" makes a lot of difference. It adds that the sponsors, researchers and host country governments should make provisions for post-trial access for all participants who still need an intervention identified as beneficial in the trial [2]. This information must be disclosed to participants during the informed consent process also [2].

The Council for International Organizations of Medical Sciences (CIOMS) puts the onus of responsibility on trial sponsors and investigators stating that: "Before undertaking research in a population or community with limited resources, the sponsor and the investigator must make every effort to ensure that any intervention introduced; product developed, or knowledge generated, will be made reasonably available for the benefit of that population or community" [1]. The 'reasonable availability' term is complex and needs to be determined on a case-by-case basis. The European Commission's European Group on Ethics in Science and New technologies recommends "a guarantee of a supply of a (proven beneficial) new drug at an affordable price for the community" [1].

The scenario is quite different in the developed world. Effective experimental interventions are usually already integrated into the health system of the industrialized nations. If not, then as a general rule, beneficial new medicines are freely supplied to all participants once the trial is completed [3]. On the other hand, participants in developing countries have limited or no access to healthcare, to begin with. That is why it raises ethical issues when it comes to conduct of trial in developing countries. Therefore, the emphasis on post-research responsibilities is not misplaced.

\section{Discussion}

So what ought to be the post research responsibilities of the research enterprise in light of the basic ethical principles that give rise to these responsibilities? Beneficence: Two general rules of beneficence are laid down by the Belmont Report, to be followed in human research. First, "Do No Harm". And secondly; "to maximize possible benefits and minimize possible harms" [3].

If we take the argument a little further, we shall see that nonmaleficence (avoiding harm) is deeply ingrained in the history of research ethics. Consider a certain population, which is already resource-poor and contributing to science by participating in a clinical trial, is abandoned as soon as the trial is over. It cannot be denied that discontinuing supply of drugs which have proven to be effective for the particular illness under study or an intervention which has proven beneficial during the trial will surely have detrimental effects on the health status of the study participants. 


\section{Needs assessment of the target population}

Before embarking on any research, the international health researcher and sponsors should take great care in assuring that the community/participants are not left 'worse off' than they already were before beginning the trial [1]. It is noteworthy that most clinical trials are conducted on chronic diseases. If a trial shows that a new treatment for a chronic disease like diabetes, hypertension or HIV is substantially more effective than the existing standard of care, it is an ethical obligation of the sponsors to provide that drug to the trial participants for as long as they require it [1].

Many public health professionals from developing countries have suggested that post-trial responsibilities be conceived of, more broadly to encompass strengthening of manpower through education and/or 'health systems reinforcement' rather than simply be confined to vague terms such as 'reasonable' and 'affordable availability' of drugs developed by the research. In a resource-poor country like Pakistan, post-research responsibilities may extend to ensuring provision of additional skilled staff or equipment to a hospital or to enhance delivery services such as those required for vaccination. The sponsors and funding agencies should focus on capacity building and strengthening health delivery systems. They should also train personnel specifically to transfer the skills so as to empower them to take charge after the research team has left.

Justice as reciprocity: The participants have contributed to the society and the sponsors and researchers owe them post-trial access to any beneficial drug or intervention developed as a result of their participation and by virtue of reciprocity. Their contribution does not end when the trial ends [3]. Follow-up of such participants after the trial is over, enables assessment of long term health impacts of an intervention and is imperative to scientific knowledge about that intervention, but more importantly, it is an obligation to ensure safety of research participants in the intervention group. Interruption of provision of high quality medicines to the participants is unfair and exploitative. The community where research has taken place should be the direct beneficiaries of the research.

Justice as fairness: It is also seen that most international health research conducted in developing countries exposing the participants to unknown risks, actually develops medicines for use in the industrialized nations [3]. The for-profit sponsors make a lot of money from results of successful research. This increases several folds, the responsibility of the sponsors and the investigators toward the participants. Just how far these post-trial benefits may extend remains a contentious issue in research ethics. But it is very clear that these points be discussed at the level of proposal development and in consultation with the local Ministry of health. This will guide researchers as to what exactly is the current need for that particular community and the expectations of the participants regarding posttrial provision.

Needless to say, the credibility of the entire research is dubious if there is no social value for the community being researched by the researchers. The research should address the health needs and problems of the community being researched.

Distributive justice: In other words, the fair distribution of benefits and burdens of research to maintain equity in research ethics [1]. Studies which are conducted on participants of one community, for the benefits to be solely enjoyed by another community rightly draw criticism.
An important addendum here is that in most cases, recruitment process of participants in developing countries is significantly undermined by a poorly communicated and hence poorly understood informed consent. The post-trial provisions and responsibilities should be clearly laid out and negotiated with, as a matter of priority not only with the participants, but with the sponsors, funding agency the local community and the ministry of health in the form of a "pretrial agreement". This will ensure avoidance of any future exploitation. It will also address, respect for persons (autonomy) of the individual participants, because they will know exactly what to expect after the trial is over and they will have a clearer picture of what they are getting into.

For instance, if a research is being conducted by a medical device manufacturer and during the study it is discovered that this new device is successful in detecting blood sugar levels more accurately as compared to all the existing devices in the market. Then the postresearch responsibility for the researchers and sponsors is to provide that device, ideally free of cost to all participants and controls. Not only that, the laboratory testing and monitoring of various other indicators of adequate sugar control, annual physical examinations although not required for the study, should also be catered for. Another manner in which sponsors and funding agencies can deliver their responsibilities after the research is to devise strategies to ensure the manufacture of generic copies of patented drugs for poor countries [4]. Randomized controlled trials of artemisinin (a Chinese herb) combination therapy for malaria were largely undertaken in Africa and Asia. As a result of the researchers' post-trial efforts price-drops have been achieved and easier-to use formulations have become available to the participants and the community.

If nothing else, then the sponsors should seek joint initiatives of international agencies and through private-public partnerships to produce affordable drugs [4]. One way is to collaborate with the Ministry of Health which agrees to pay a proportion of the cost of the drug/intervention. This will also indicate a political will and commitment of the local authorities and the trial sponsors will be under increased pressure to contribute to the costs. There are many private organizations like GAVI (Global Alliance for Vaccination and Immunization) or Global fund for HIV, Malaria and Tuberculosis [1] that can cover costs based on humanitarian grounds, if they are involved at the research proposal stage. A concern is that post-trial responsibilities may discourage international research, but that should not be the case. There are many ways that sponsors can circumvent problems of financial constraints and it has been done before and these problems are not unsolvable. Medecins Sans Frontieres (MSF) is conducting a study of the effectiveness of a nutritional intervention in catch-up growth of children after an acute episode of malaria in Africa [5]. The supplement is expensive and to make the supply of this supplement sustainable beyond the study, MSF is currently working on price reductions of this supplement as well as making efforts to increase its supply through local production. They have also made a commitment to stay in the community for at least 2 years after the end of the study.

If a social sciences research is being conducted to determine whether the basic risk factor of glue-sniffing and begging in street children is poverty or lack of primary education, then the sponsor may fulfill their post research responsibility by setting up the infrastructure of a school for the study participants where they can get quality education and a certain fixed stipend as an incentive to go to school. This will have a dual purpose, firstly, the children will be off the streets 
Citation: Khan N (2014) The Post-Research Ethical Obligations of the Research Enterprise in Developing Countries. J Clinic Res Bioeth 5: 194.

Page 3 of 3

at least during the day and secondly they will get a purpose in life, with education. They will also be able to get financial aid as a result and it is highly likely that they may be able to support themselves if not their families also in a dignified manner. The sponsor and investigators will be 'giving back' to the entire community by uplifting them. This is a social responsibility of researchers. Such social service goes a long way in expressing some gratitude to the community which has contributed so significantly to the researchers' study objectives. Direct feedback from participants has revealed that even digging a few boreholes in an area where water shortage is a problem, or providing adequate supply of chlorine tablets for water purification, or setting up a water filtration plant in the locality helps. Such measures create a bond amongst researcher and participant, the benefits of which are reaped for a long time even after the study has ended.

Finally, a very important responsibility of the research enterprise is the Dissemination of results of the study to the participants and to the entire community. The results of the study should be discussed in detail with the participants and the community leaders. This can be achieved by conducting "dissemination workshops" [6]. Not only that, access to these results is to be ensured in order to maintain transparency.

According to the latest guidelines released by WMA, "Negative and inconclusive as well as positive results must be published or otherwise made publicly available. Sources of funding, institutional affiliations and conflicts of interest must be declared in the publication" [2]. Furthermore, every research study involving human subjects must be registered in a publicly accessible database before recruitment of the first subject [2]. In developing countries, more than anywhere else, community engagement throughout the research is to be encouraged.

Involvement of the participants and the community gives them a true sense of partnership with the researcher which further strengthens the activities related to the project.

\section{Summary}

There are many ethical obligations and post-research responsibilities that international health researchers owe to the recruited participants and their communities in developing countries. Based on the above arguments, it is evident that each study population will have a different need and the post- trial benefits should be best tailored to meet those needs. Some conscientious researchers, sponsors and funding agencies conducting the research are making sure they fulfill their responsibilities after the trial has ended; however, strict implementation of existing guidelines is required to make this process a binding norm for all international researchers and agencies in order to ensure that human beings are not exploited in the name of research.

\section{References}

1. Greenwood B, Hausdorff WP (2003) After the trial is over: the ethical issues

2. (2013) WMA Declaration of Helsinki Ethical Principles for Medical Research Involving Human Subjects

3. Zong Z (2008) Should Post-trial provision of beneficial experimental interventions be mandatory in developing cointries? J Med Ethics: 188-192

4. (2004) Double Standards in medical research in developing countries. Ruth Macklin (Ed): 280.

5. Schopper D, Upshur R, Matthys F, Singh JA, BAndewar SS, et al.(2009) Research ethics review in humanitarian contexts: The experience of the independent ethics review board of Medecins Sans Frontieres. PLoS Med 6: e1000115

6. Mfutso-Bengo J, Masiye F Ndebele P (2008) Disseminating research results to research participants and their communities. Malawi Med J. 20: 64-66 